\title{
Skills and Regional Entrepreneurship Capital Formation A Comparison Between Germany and Portugal
}

\author{
Mendonça, Joana ; Grimpe, Christoph
}

Document Version

Accepted author manuscript

Published in:

Journal of Technology Transfer

DOI:

10.1007/s10961-015-9444-5

Publication date:

2016

License

Unspecified

Citation for published version (APA):

Mendonça, J., \& Grimpe, C. (2016). Skills and Regional Entrepreneurship Capital Formation: A Comparison

Between Germany and Portugal. Journal of Technology Transfer, 41(6), 1440-1456.

https://doi.org/10.1007/s10961-015-9444-5

Link to publication in CBS Research Portal

\section{General rights}

Copyright and moral rights for the publications made accessible in the public portal are retained by the authors and/or other copyright owners and it is a condition of accessing publications that users recognise and abide by the legal requirements associated with these rights.

Take down policy

If you believe that this document breaches copyright please contact us (research.lib@cbs.dk) providing details, and we will remove access to the work immediately and investigate your claim. 


\title{
Skills and Regional Entrepreneurship Capital Formation: A Comparison between Germany and Portugal Joana Mendonça and Christoph Grimpe
}

Journal article (Post print version)

\begin{abstract}
This article was originally published in Journal of Technology Transfer. First published
\end{abstract} online: October 7, २०८८.

The final publication is available at Springer via http://dx.doi.org/10.1007/s10961-

015-9444-5.

Uploaded to Research@CBS: March 2016 


\title{
Skills and regional entrepreneurship capital formation: A comparison between Germany and Portugal
}

\author{
Joana Mendonça ${ }^{a}$ and Christoph Grimpe ${ }^{b}$ \\ ${ }^{a}$ IN+, Instituto Superior Técnico, Technical University of Lisbon (Portugal) \\ ${ }^{\mathrm{b}}$ Copenhagen Business School (Denmark) \\ ZEW Centre for European Economic Research, Mannheim (Germany)
}

Forthcoming in the Journal of Technology Transfer. The final publication is available at http://link.springer.com.

\section{Corresponding author:}

Christoph Grimpe

Copenhagen Business School

Dept. Innovation and Organizational Economics

Kilevej 14A

2000 Frederiksberg, Denmark

Phone: +45-38152530

E-mail: cg.ino@cbs.dk

\section{Acknowledgements:}

The authors thank Melanie Arntz, Terry Gregory, Georg Metzger and Roberto Patuelli for the provision of data, and Christian Rammer and participants at the ZEW Brown Bag seminar for helpful comments and discussions. Moreover, we thank the special issue editors Rosa Caiazza and David Audretsch as well as two anonymous reviewers for helpful comments. 


\title{
Skills and regional entrepreneurship capital formation: A comparison between Germany and Portugal
}

\begin{abstract}
Entrepreneurship capital has frequently been characterized as an important determinant of regional economic growth. Yet, we have limited knowledge about what explains why certain regions are more successful in creating entrepreneurship capital in general and in particular in technology- and knowledge-intensive sectors. In this paper, we shed light on the skill base of a region in terms of its endowment with human capital and the composition, i.e. specialization or diversity, of skills. Moreover, we look at the context in which entrepreneurship capital formation takes place by focusing on differences in the institutional infrastructures for entrepreneurship in two European countries: Germany and Portugal. Based on harmonized datasets, our results indicate important differences between the countries. Specifically, our results suggest that both specialization and diversity theories hold, and that the effects are thus contingent on regional factors.
\end{abstract}

Keywords: Regional entrepreneurship capital, skills, cross-country comparison JEL-Classification: J24, L26, O57, R11 


\section{$1 \quad$ Introduction}

It has become a part of conventional wisdom that most developed market economies are nowadays based on knowledge (Griliches, 1979). Moreover, knowledge is likely to spill over, which refers to the fact that organizations like universities, research centres and firms but also individuals benefit from others' research and development (R\&D) activities (Arrow, 1962). Knowledge spillovers have been argued to encourage knowledge-based entrepreneurship within regions. The effectiveness of knowledge spillovers leading entrepreneurs to exploit a commercial opportunity has frequently been suggested to depend on a region's entrepreneurship capital, defined as the result of a region's legal, institutional and social factors conducive to entrepreneurship, or the capacity of a society to generate new firms (Audretsch and Keilbach, 2004a, 2004b). Entrepreneurship capital has been shown to depend on factors creating or stimulating entrepreneurial opportunities, such as the economic output of a region, and on factors influencing the general economic situation, such as regional unemployment or industrial diversity (Audretsch and Keilbach, 2008). However, prior literature has paid little attention to the role that human capital plays in the creation of entrepreneurship capital. This is surprising since the generation of new knowledge requires qualified human capital, and so does the ability to absorb such knowledge, as individuals need to be able to recognize and absorb this knowledge and to further transmit it or bring it to the market through entrepreneurial activity (Cohen and Levinthal, 1989).

Hence in this paper, we suggest that a region's endowment with human capital is a major driver of knowledge-based entrepreneurship capital. Moreover, we suggest that positive externalities in terms of creating entrepreneurship capital may arise from a certain composition in skills. Borrowing arguments from the literature on industrial diversity (e.g., Glaeser et al., 1992), our paper explores the relationship of both skill diversity and skill 
specialization with regional entrepreneurship capital formation. We do so in the context of a cross-country comparison, choosing two European economies, Germany and Portugal, as the empirical basis for our investigation. Conducting a cross-country comparison necessarily requires a justification of the choice of countries. Since our analysis is exploratory in nature, we decided to compare two countries with largely diverging structural and economic patterns, in order to investigate the associations of human capital and skill composition with regional entrepreneurship capital formation in, what we will refer to, institutional infrastructures for entrepreneurship.

Our empirical analyses are based on data from the 439 NUTS-3 regions in Germany and the 28 NUTS-3 regions in Portugal for the period from 2000 to 2004. Besides general entrepreneurship capital, we consider sector-specific entrepreneurship capital, specifically technology- and knowledge-oriented manufacturing and services sectors since the extent of knowledge spillovers can be assumed to be higher in these sectors, and they capture the risky nature of entrepreneurial activity (Audretsch and Keilbach, 2004a). Our results confirm the high importance of human capital for creating entrepreneurship capital in both countries. However, the results show contradicting relationships for skill composition: while entrepreneurship capital formation in Portugal benefits from higher skill specialization, there are higher benefits from skill diversity in Germany.

We contribute to the literature in three ways. First, we shed light on an understudied area in the literature on entrepreneurship capital formation by focussing on the role played by human capital and a particular composition of skills. In that sense, we extend the knowledge spillover based view of entrepreneurship (Audretsch et al., 2005) by putting emphasis on the individuals and their endowment with certain skills as a conduit facilitating knowledge spillovers and subsequent exploitation of entrepreneurial opportunities. Second, our research contributes to the ongoing debate on skilled labour as a central determinant of economic 
growth, particularly in knowledge-based industries (Lucas, 1988; Boschma and Lambooy, 1999). Based on a fine-grained measure of regional skill composition, our research provides implications for regional policy making aiming at improving the conditions for entrepreneurial activity. Third, our research provides a nuanced analysis of different types of entrepreneurship capital in technology- and knowledge-based sectors and focuses on the role that different institutional infrastructures for entrepreneurship play for entrepreneurship capital formation.

The remainder of this paper is organized as follows. The next section outlines our theoretical background and details our research questions on the relationship between human capital, the composition of skills and the formation of entrepreneurship capital. Section 3 presents our data and methodology. The results are presented and discussed in Section 4. Section 5 concludes with implications and an outline of potential future research avenues.

\section{Theoretical background}

\section{$2.1 \quad$ The importance of entrepreneurship capital}

A growing stream of literature has looked into the factors stimulating regional entrepreneurial activity and identified entrepreneurship capital as "the milieu of agents, routines, traditions and institutions of an economy, a region or a society that is conducive to entrepreneurial behavior and a culture of risk taking” (Audretsch et al., 2008: 690). In other words, entrepreneurship capital accounts for a number of different legal, institutional and social factors, which create the conditions for entrepreneurial activity to take place, including high endowment with individuals who are willing to take the risk and to explore commercialization of ideas by starting a new firm. These factors taken together constitute entrepreneurship capital and create the capacity of an economy for entrepreneurial activity (Audretsch and Keilbach, 2004a, 2004b, 2007, 2008). 
Audretsch and Keilbach (2004a) suggest entrepreneurship capital to be a component of social capital which has an impact on economic growth, as it creates the necessary conditions for entrepreneurship to occur and for taking knowledge, which has not yet been commercialized, to the market. Social capital leads to regional development, directly or indirectly, by contributing to an environment that promotes economic activities (Baumgartner et al., 2013). On the opposite, regions with lower entrepreneurship capital hinder the existing ability of individuals to explore commercial opportunities and start new firms. Entrepreneurship in that sense can be seen as a process of exploiting opportunities that exist in the environment, converting ideas into successful businesses and creating value through innovation (Shane, 2000).

Audretsch and Keilbach (2008) find that knowledge-based entrepreneurship capital is driven by local levels of knowledge creation and the acceptance of new ideas, indicating that local knowledge flows play an important role. Entrepreneurship capital can be seen as a mechanism for knowledge spillovers because it enables the exchange and flow of ideas as well as the startup of new firms, since knowledge and ideas are being exploited that, under different circumstances, would not be commercialized. Thus, entrepreneurship capital promotes economic performance by serving as a conduit of knowledge spillovers. In addition, entrepreneurship capital may impact economic growth by increasing competition as well as diversity among the firms in a market (Audretsch and Keilbach, 2004b). In fact, Audretsch and Keilbach (2004b) propose that entrepreneurship capital constitutes an omitted factor in the neoclassical growth models in order to explain economic development.

The above arguments suggest the effectiveness of knowledge spillovers to be driven by the availability of skilled human capital since individuals need to be able to recognize, absorb and commercialize knowledge in order to become entrepreneurial (Cohen and Levinthal, 1989). In 
the following, we will look in more detail into the importance of human capital and the particular composition of skills in a region for creating entrepreneurship capital.

\section{$2.2 \quad$ Human capital and skill composition}

As knowledge becomes more important as a factor of production, knowledge spillovers also gain significance as a source of economic growth. Variations across countries and regions in entrepreneurial activity can be a source of different efficiencies in knowledge spillovers, and eventually in economic growth (Acs and Varga, 2005). There are several channels through which knowledge can spread to firms or individuals: it can be codified in books and other publications; it can be conveyed through public presentations of various types, such as seminars and conferences; it can be gained through reverse engineering and other purposive search processes. Knowledge may also be embedded in people, for example graduates who take a job at a firm or start their own business. The extent to which knowledge flows through these different channels depends upon the recipient's skills and abilities and the nature of the knowledge itself (for example, level of complexity and level of tacitness) (Geroski, 1995).

Jaffe et al. (1993) posit that the ability to receive spillovers may be a reason for the concentration of activity. Since knowledge is a public good, the general underlying assumption is that new knowledge is automatically available to all agents in the economic process (Audretsch and Keilbach, 2008). However, not all agents are able to use the knowledge available in an equal way, and the ability to receive spillovers is likely dependent on the availability of human capital to receive it, absorb it and use it (Cohen and Levinthal, 1989). Consequently, differences in the endowment of regions with human capital will likely generate differences in the formation of entrepreneurship capital.

While the importance of human capital per se seems obvious, little is known about the importance of the composition of human capital in a region. In this respect, the skill base may 
act as an important factor to explain growth through entrepreneurial activities (Lucas, 1988; Boschma and Lambooy, 1999). Skilled labour is one element of the human capital available in a region. We suggest in the following that the regional composition of human capital in terms of skills, professions or disciplines matters for the formation of entrepreneurship capital. We argue that mechanisms similar to the effects of the composition of the industrial base may be at work which have been found to be an important predictor of growth differences between regions (see Beaudry and Schiffauerova, 2009, for an overview). Applying the "Marshallian specialization" and the "Jacobian diversity” arguments to the labor market therefore leads us to the question whether entrepreneurial capital formation in a region will benefit more from either a specialized or a diversified skill base.

The Marshallian specialization argument, on the one hand, suggests that regions specialized towards a particular industry may perform better. Marshall (1920) defined three factors that characterize a specialized industrial base: labor market pooling, availability of intermediate inputs into production processes, and knowledge spillovers between firms. These factors have also been identified as stimulating the entry of new firms into those regions that already have a specialized industrial base. This is partly due to higher innovation rates in that industry because knowledge may spill over easily between similar firms which can be assumed to have higher absorptive capacity for similar knowledge. Applying this logic to our context, higher skill specialization may be related to higher levels entrepreneurship capital formation.

On the other hand, Lee et al. (2004) argue that entrepreneurial activity requires not only a productive and supportive business climate along with an educated population, but also a climate where creativity, diversity, and innovation are encouraged and valued. They suggest more diverse regions to have lower entry barriers, which make it easier for human capital with various backgrounds to enter the region and propel entrepreneurial activity. In fact, Feldman and Audretsch (1999) find evidence that specialization of economic activity does not promote 
innovative output which may, as a consequence, spur entrepreneurial activity. Rather, they find evidence that diversity (according to the "Jacobian diversity" argument) across complementary economic activities sharing a common science base is more conducive to innovation. Moreover, de Vor and de Groot (2010) find that specialization hampers employment growth. Andersson et al. (2005) relate patent activity to measures of localization and urbanization, to the industrial composition and size distribution of firms, and to the regional distribution of human capital. They find that patents are responsive to the spatial distribution of workers at different levels of education and the distribution of private and public $R \& D$ facilities. If levels of specialization are so high that, in the extreme case, all individuals in the region have the same profession, than it is less likely that individuals can share and explore new knowledge, thus leading to lower levels of entrepreneurial activity.

In sum, the literature on the effects of industrial diversity for innovation, entrepreneurship and growth is inconclusive whether concentration or diversity is more beneficial (Beaudry and Schiffauerova, 2009). In our human capital context, both concentration and diversity arguments are likely to be positively associated with the formation of entrepreneurial capital, making the question on the actual relationship an empirical one. Hence, in the next section, we turn to the issue of institutional infrastructures for entrepreneurship in order to explore the role that human capital and skill composition may play in different country contexts.

\subsection{Differences in institutional infrastructures for entrepreneurship}

The previous section has made it clear that there are indications that both specialization and diversity of the skill base may be favorable for entrepreneurship capital formation in a region. It is therefore important to look at the empirical context which we refer to as the institutional infrastructures for entrepreneurship. In fact, one possible explanation for performance differences between countries is that some of the individual activities that arise from the division of labor, such as property rights, regulation, infrastructure, specific labor skills, 
cannot be imported, which implies that countries need to have them locally available in order to grow (Hidalgo and Hausmann, 2009). Audretsch and Keilbach (2007, 2008), for example, find that knowledge-based entrepreneurship capital is driven by local levels of knowledge creation and the acceptance of new ideas, indicating that local knowledge flows play an important role. According to these authors, entrepreneurship capital is a phenomenon driven by local institutions and culture, and that is therefore locally bounded. We argue that the institutional infrastructures for entrepreneurship will vary particularly at the national level and to a much lower degree at the regional level. Intra-national infrastructures feature a common legal and institutional framework, together with a rather homogeneous culture. Differences in institutional infrastructures for entrepreneurship and their effect on the relationship between specialization, diversity and entrepreneurial activity may therefore be properly addressed by means of a comparative study between two countries.

For this purpose, our research draws a comparison between Germany and Portugal. Both countries are member states of the European Union but at the same time fairly different in terms of economic and social characteristics and, hence, institutional infrastructures for entrepreneurship. Table 1 shows some economic characteristics of both countries (close to the time-frame of our sample), which reveal these differences.

\section{[Insert Table 1 about here]}

First of all, Germany is much larger in size, both in terms of area and population. Its GDP is more than 20 times as high as in Portugal. The average income per capita is roughly the double. While Germany has a higher unemployment rate than Portugal, inflation is higher in Portugal. Germany has a higher population density, and a higher share of the population lives in urbanized regions.

In addition to structural economic differences, studies have shown that the countries possess significant differences in the industrial structure, which makes their comparative analysis an 
interesting one. Germany is an export-oriented country with an established high-tech industry and a high share of innovators, while Portugal has an economy less dependent on knowledge and technology, where most exports come from labour-intensive sectors, with a focus on the services sector and a low share of innovators (Faria and Schmidt, 2012; Faria and Sofka, 2010). In addition, these two countries exhibit different entrepreneurial behaviors: According to the Global Entrepreneurship Monitor (GEM) report, Germany had a relatively low level of entrepreneurial activity, even when compared with other industrialized economies, ascribed mainly to the lack of entrepreneurial spirit among the majority of the population. Nevertheless, knowledge-intensive start-ups were relatively frequent in Germany (GEM Report, 2004). Portugal showed higher rates of entrepreneurial intentions, and higher business ownership rates. The GEM results also showed that Germany possessed good physical infrastructure and good governmental support for entrepreneurs, but higher opportunity cost for entrepreneurship, due to a high level of opportunities in the labor market. In addition, the GEM suggested that there is a lack of cultural and social values and norms related to entrepreneurship, and a poor entrepreneurial climate in the education system. The report also showed that Portugal had excellent physical infrastructure and competent professionals too, which facilitated entrepreneurial activity, sharing with Germany the lack of social values and norms related to entrepreneurship. This situation has not changed much compared with the latest GEM Report for 2014 (GEM Report, 2014).

In sum, we expect these differences between Germany and Portugal to have repercussions for the role that human capital and skill composition play for the formation of regional entrepreneurship capital. 


\section{$3 \quad$ Methods}

\subsection{Data}

We use two harmonized datasets for Germany and Portugal based on the NUTS-3 regional classification level in the period from 2000 to 2004. NUTS stands for "Nomenclature of Units for Territorial Statistics” and is a geocode standard for referencing the subdivisions of countries for statistical purposes. The different NUTS levels refer to comparably sized regions within Europe with the NUTS-3 level being the most detailed level available. There were 28 regions ${ }^{1}$ in Portugal and 439 regions ("Landkreise” and "kreisfreie Städte”) in Germany during this period. ${ }^{2}$ While the NUTS-3 level constitutes an administrative and not a functional delineation of regions which could be argued to bias the results (e.g., Eckey et al., 2007), there are considerable advantages with regard to data availability and collection. In that sense, our choice of regional aggregation level follows prior research that employs similar variables (e.g., Audretsch and Keilbach, 2008; Audretsch et al., 2008).

The Portuguese data are drawn from the Quadros de Pessoal (QP) dataset, gathered by the Portuguese Ministry of Social Security on the basis of an annual mandatory survey. This is a longitudinal matched employer-employee database which includes extensive information on all private firms, establishments and workers in the Portuguese economy since 1986. The QP database covers on average over 145,000 firms, 170,000 establishments and two million workers in each annual return which are fully linked through the use of a unique identification number, thus allowing for the recognition of both new entrants and exiting firms, as well as

1 We excluded the autonomous regions of Azores and Madeira due to data availability.

2 In November 2001, two regions in the state of Lower Saxony were merged. From 2002 on the values of the variables for the formerly independent regions are thus equal. Germany has experienced several changes in its regional structure over the past decades which creates particular challenges for the collection of data. Widespread changes occurred from 2007 to 2011, resulting in only 402 NUTS-3 regions in 2013. 
the opening and closure of subsidiary establishments. For each firm, data are available for size, age, location, sector and number of establishments. Data on business owners and employees for each firm and establishment include gender, age, function, tenure, earnings and working hours, schooling and skill levels (see Cabral and Mata (2003) for a description of the quality and coverage of the data).

New firm entry in all sectors as well as in two knowledge-intensive subsectors, i.e. high- and medium-high-technology manufacturing as well as technology- and knowledge-intensive services, was identified and assigned to the Portuguese NUTS-3 regions. Additional data concerning the NUTS-3 regions were gathered from the National Institute of Statistics (INE).

The German data are based on information from the German statistical office (Destatis) and Eurostat. Information on firm entry stems from the Mannheim Foundation Panel, a database which is compiled annually by the Centre for European Economic Research (ZEW) in Mannheim, Germany. Data are based on information from the Creditreform agency and cover virtually the population of firms in Germany. Data on the regional skill base are taken from the IAB Linked Employer-Employee Panel (LIAB) which combines data from the IAB Establishment Panel and the Employment Statistics Register. The IAB Establishment Panel is based on an annual survey of establishments in Western Germany and has been administered since 1993 by the research institute of the Federal Employment Services in Nuremberg, Germany. Establishments in Eastern Germany entered the panel in 1996. The database is therefore a representative sample of German establishments employing at least one employee who pays social security contributions.

\subsection{Measures}

Both datasets have been harmonized to contain the same variables that can be used for our study. Our dependent variable is entrepreneurship capital. We follow Audretsch and Keilbach 
(2004a, 2008) who argue that entrepreneurship capital is based on a latent measure which reflects the underlying but unobservable concept of regional entrepreneurship capital, namely the startup of a new firm. We use the new-firm startup rate, which is calculated as the number of startups in a region divided by the population aged 18 to 65 (per thousand), as our measure for entrepreneurship capital. Since the degree to which knowledge spillovers are required for entrepreneurship may vary between startups, we construct three measures of entrepreneurship capital, reflected by the total number of startups, the number of startups in high- and mediumhigh-technology manufacturing and the number of startups in technology- and knowledgeintensive services, which follows an OECD classification of industries (OECD, 2002). Hightech manufacturing includes industries like pharmaceuticals, electronics or instruments; technology- and knowledge-intensive services include ICT services or R\&D services.

We measure the skill base of a region by two measures. ${ }^{3}$ The first is a standard measure for the general human capital available in a region (Audretsch and Feldman, 2004; Andersson et al., 2005). It is defined as the share of the employees with college education over the total number of employees contributing to social security. The second measure accounts for the specialization of skills in a region, based on a simple concentration measure. This measure is based on the distribution of employees amongst a group of occupations in science and engineering, i.e. in physics and chemistry; mathematics and computer sciences; engineering

3 For Germany, using data from the LIAB involves the restriction that some NUTS-3 regions, particularly in Eastern Germany, have been aggregated to microcensus regions in order to fulfil the minimum size requirements of 100,000 inhabitants. As a result, the 439 NUTS-3 regions are combined to 343 microcensus regions. Our analyses are based on the NUTS-3 regions, and therefore the two measures for the skill base had to be disaggregated in order to be merged with the other regional data. As both measures are shares, we decided to use the same value for every NUTS-3 region combined into a microcensus region, thus slightly reducing the variance for these measures. 
and architecture; life sciences; health sciences; social sciences; artists and writers. ${ }^{4}$ The specialization measure is calculated as follows:

$$
s_{i}=\frac{\max \left(x_{i j}\right)}{\sum_{1}^{j} x_{j}},
$$

where $i$ is the region and $j$ the occupation. Hence, for every region the largest group of employees as a share of the total workforce is taken to depict regional skill specialization. A high value of $s_{i}$ thus shows high concentration while a low value would hint at high diversity. Moreover, we introduce control variables for other regional factors which are likely to affect the number of new firms in each region. The logarithm of the total population is used as a measure of regional demand size, which should represent an attraction for start-ups. It is also a measure for the size of the regional labor pool which refers to the supply of potential entrepreneurs. The annual growth of the GDP is introduced in the estimation to account for the level of economic development and dynamics of the regions. Regions with higher GDP growth should also be more likely to have a higher number of new firms entering. In addition, we include the unemployment rate which depicts the role of unemployed persons in new firm formation activity (Fritsch and Falk, 2007). We expect that higher unemployment rates may positively affect entry of firms in all sectors, but will negatively affect entry in more knowledge- and technology-intensive sectors, which are more likely to depend on other sources of human capital. In addition, we introduce year dummies to account for time-specific influences, such as differences in the effects of business cycles across regions. Finally, we add dummies for the NUTS-1 or NUTS-2 regions which are motivated in the following section.

4 These professions refer to the International Standard Classification of Occupations (ISCO-88) of the International Labour Organisation (ILO), Occupations in Science and Engineering Codes 211-214, 221-223, 244, 245. 


\subsection{Model}

We conduct separate analyses for Germany and Portugal and data are pooled for the years 2000 to 2004. We estimate a series of regression models with Driscoll-Kraay standard errors for coefficients estimated by pooled OLS. Driscoll-Kraay standard errors are heteroskedasticity consistent and robust to general forms of spatial and temporal dependence which is likely to be the case in our data (Driscoll and Kraay, 1998). All explanatory variables are lagged by one year to limited endogeneity concerns, i.e. they refer to the period 2000 to 2004 while the dependent variables refer to the period 2001 to 2005. Moreover, in order to more explicitly address potential spatial autocorrelation, we estimate a spatial cross-regressive model that accounts for the effects of neighboring regions by including dummy variables for the 16 Federal States in case of Germany and for the 5 major provinces (NUTS-2) in case of Portugal (Fritsch and Falck, 2007).

\section{$4 \quad$ Results}

\subsection{Regional distribution of entrepreneurial activity and descriptive statistics}

We start off with a look at the regional distribution of the startup rate, i.e. entrepreneurship capital, in Germany and Portugal. Figure 1 shows the average annual startup rate from 2000 to 2004 for new firms in the 28 Portuguese NUTS-3 regions. The map reveals a high concentration of firms along the coastline, with greater incidence in the north of the country. This is consistent with the work of Cesário and Vaz (2004) who found that, for Portugal, certain regions generate a better entrepreneurial environment and have a better potential for the development of new businesses. The two NUTS-3 regions containing the main cities of Lisbon and Oporto distinguish themselves from the remaining regions. This evidence has been shown previously by Baptista and Preto (2007) who observe that only the large metropolitan regions of Lisbon and Oporto (NUTS-3) can be considered as highly 
agglomerated and are the ones that display higher startup rates. In fact, their work suggests that the NUTS-3 regions comprehending Lisbon and Oporto can be called 'gazelle regions', whereas the remaining 'elephant regions' display below average levels of agglomeration and business dynamics. Nevertheless, observing the map in Figure 1 allows for the distinction of other groups. From these, the regions with highest entrepreneurship capital are in the North, Ave and Tâmega, Setúbal south of Lisbon, and the Algarve, known for its touristic development. The group right after contains the two regions of Cávado and Oeste, which display higher entrepreneurship capital, associated with the strong cluster of glass and moulding industries which had developed over the years in those areas. The remaining regions consist of the inland regions which display a relatively low level of entrepreneurship capital.

[Insert Figure 1 about here]

Figure 2 presents the average annual regional startup rates for Germany. It can be clearly seen that East Germany, with the exception of Berlin and very few other cities, still suffers from de-industrialization and migration into the West, following the liquidation of most of the dilapidated industrial base. Other dynamic regions include the Stuttgart, Hamburg, Hannover and the Ruhr area with high levels of entrepreneurship capital. In the south of the country, the region of Munich stands out from the remaining regions. Generally speaking, the distributional pattern of entrepreneurship capital seems to reflect the levels of regional economic power (Grimpe and Patuelli, 2011).

[Insert Figure 2 about here]

Table 2 and Table 3 show the descriptive statistics for the variables under study in both countries. Startup rates for Germany and Portugal turn out to be in about the same magnitude with Portugal having slightly higher rates. In both countries only a small fraction of entries is in high- and medium-high-technology sectors. Significantly more entries can be observed in 
technology- and knowledge-intensive services. Regarding the human capital, 6 percent of the workforce in Portugal holds a college degree while this figure is 8 percent for Germany. With respect to the specialization of skills in the regions, the statistics reveal that specialization is on average higher in Germany, however also with a higher variation across the regions.

[Insert Table 2 about here]

[Insert Table 3 about here]

\subsection{Estimation results}

Results for Portugal from the pooled OLS models are presented in Table 4. Regarding the first variable capturing the region’s skill base, human capital, we surprisingly find a significant and negative relationship with entrepreneurship capital in all sectors. The coefficient is not significant for entrepreneurship capital in the two subsectors. This indicates that in Portugal the vast majority of startups are founded out of necessity while more highly skilled persons prefer wage employment. This may particularly reflect firm entry in Portugal's tourist destination regions. With respect to the second variable capturing the skill specialization, our results indicate that higher specialization propels entrepreneurship capital especially in highand medium-high-technology manufacturing sectors. These results are in line with Rosenthal and Strange (2005), who found that for the US local area industrial specialization was positively related to new firm entry and employment growth among the new firms. They also found that the influence of this specialization decreases with distance. Baptista and Preto (2007) suggest that the creation of knowledge-based firms benefits from high levels of agglomeration and business dynamics to induce positive supply side spillovers that have a positive overall effect on subsequent employment change, but that this effect is not clearly true for other types of firms. 
With respect to the control variables, a larger region in terms of population is also conducive to higher entrepreneurship capital. This indicates that both the local demand is higher but also the supply with labor. Regional GDP growth shows a significant and positive relationship with entrepreneurship capital in all sectors, but significant and negative relationship with entrepreneurship capital in the two subsectors. It is likely that new firm entry in these sectors is less dependent on macro-economic conditions, thus leading to this result. Finally, the unemployment rate turns out to be insignificantly related to the formation of entrepreneurship capital. This indicates that the formation of entrepreneurship capital particularly in the two subsectors is not related to unemployment, since these firms are started by people with higher levels of qualification who are less likely to come from unemployment. In fact, Zucker et al. (1998) found that the entry of new biotech firms is positively affected by the presence of star scientists, major universities, and federal research grants in a region. Highly skilled people are generally less likely to become unemployed.

[Insert Table 4 about here]

Table 5 shows the results for Germany. Starting with the human capital, the results show positive and significant effects for all sectors, indicating that highly qualified employees matter considerably for entrepreneurship capital formation in Germany. Moreover, we find a significant and negative relationship between skill specialization and entrepreneurship capital formation in all sectors as well as in technology- and knowledge-intensive services. The two measures for a region's skill base thus turn out to have opposite signs for Portugal and Germany. As a consequence, it seems that higher diversity, instead of higher specialization of skills as in Portugal, increases entrepreneurial activity in Germany, providing support for the Jacobs diversity argument.

Regarding the control variables, it turns out that a larger population negatively influences entrepreneurship capital formation while the GDP growth shows no significant relationship. 
As expected, there is a negative relationship between the unemployment rate and entrepreneurship capital formation in the two subsectors.

\section{[Insert Table 5 about here]}

Our findings for the two countries are in stark contrast to each other which requires interpretation. While the specialization of skills seems to foster entrepreneurship capital, at least in one subsector, in Portugal, it is diversity that propels entrepreneurship capital in Germany. Hence, our results suggest that both specialization and diversity theories hold in the context of regional skill composition. We had argued before that a key role in understanding these results has to be played by the institutional infrastructures for entrepreneurship. Maskell and Malmberg (1999) argue that proximity between firms plays a role in learning processes and that knowledge creation is supported by the institutional embodiment of tacit knowledge, which is more important for certain industries. The authors suggest that sustainable competitiveness requires the ongoing renovation of resources and obsolete structures and the renewal of economically important national or regional institutions. This institutional context may explain differences in results between Portugal and Germany and we can attribute the different effects to differences in the institutional infrastructures for entrepreneurship and in the ability of regions to renew these infrastructures. They may be important moderators for the relationship between skill specialization, diversity and new firm entry.

Another issue explaining these results is the complexity of production, as explored by Hidalgo and Hausmann (2009). According to these authors, more diversified countries produce more complex products, in the sense that they require a wider combination of human capabilities, and higher complexity is associated with higher economic growth. In addition to the presence of strong industrial bases, most of the well performing economies share other common features. One is diversification of activities, meaning that the economic output and that of industrial manufacturing in particular is distributed across a broad set of activities, which 
allows for mitigating risks but also for enhancing the capacity of the innovation system and the growth potential of the economy as a whole.

\section{$5 \quad$ Conclusion and implications}

In this paper we analyze the relationship between the regional skill base and the formation of entrepreneurship capital. Particularly, we are interested in whether a more specialized or a more diverse skill composition in regions affects the level of entrepreneurship capital in general and in a number of knowledge-intensive subsectors. Our analysis is carried out in the context of a comparative study between Germany and Portugal, leading to different results for our measures of the regional skill base. These results suggest that both specialization and diversity theories hold, and that the effect may thus depend on other more local and regional factors, i.e. specific institutional infrastructures for entrepreneurship. However, based on our models it remains an open question how exactly these infrastructures come into play as we did not identify specific measures to address this issue. Future research should therefore try to explore the interaction between the regional skill base and institutional infrastructure for entrepreneurship in more detail.

There are several implications that can be drawn from this study. Regional development policies directed at creating entrepreneurship capital should acknowledge that both specialization and diversity of the regional skill base may benefit entrepreneurship instead of promoting, all too generally, the clustering of certain industries. Our research provides an indication that diversity or specialization may depend more on the institutional and contextual settings, and may be dependent on the level of diversity of the industrial structure. These results are in line with the results obtained by Hidalgo and Hausmann (2009), who argue that the diversity of capabilities of regions and nations will determine the complexity of the industrial structure, and affect economic growth. 
The reason for this may be that the effectiveness of knowledge spillovers is contingent to the institutional infrastructures and that the effectiveness may either be spurred through specialization or diversity. In addition, these results indicate that policy measures fostering new firm formation, especially in knowledge intensive sectors, should be considered on a more local level, considering the specificities of each region, and that there is no recipe for success in what concerns the formation of clusters. Our results also point out the need for integration of regional industrial policy with education and science policy, which provide the base for the level of specialization of the work force, and that a dynamic approach to the process of building knowledge-based societies is required for an understanding of the coevolution of human capital formation and research capacity (Heitor et al., 2014). 


\section{References}

Acs Z. and Varga A. (2005) Entrepreneurship, agglomeration and technological change, Small Business Economics, 24, 323-334;

Arrow K. (1962) The economic implications of learning-by-doing, Review of Economic Studies, XXIX (June), 155-173.

Andersson R., Quigley J. M. and Wilhelmsson M. (2005) Agglomeration and the spatial distribution of creativity, Papers in Regional Science, 84, 445-464;

Audretsch D. B. and Feldman M. P. (2004) Knowledge spillovers and the geography of innovation, Chapter 61 in Handbook of Regional and Urban Economics, vol. 4, Amsterdam: Elsevier, 2713-39;

Audretsch D.B. and Keilbach M. (2004a). Does entrepreneurship capital matter? Entrepreneurship Theory and Practice 28, 419-429;

Audretsch D.B. and Keilbach M., (2004b). Entrepreneurship capital and economic performance. Regional Studies 38, 949-959;

Audretsch, D.B., Keilbach, M. and Lehmann, E. (2005). The knowledge spillover theory of entrepreneurship and technological diffusion. In Gary D. Libecap (ed.) University Entrepreneurship and Technology Transfer (Advances in the Study of Entrepreneurship, Innovation \& Economic Growth, Volume 16), Emerald Group Publishing Limited, 6991 ;

Audretsch D.B. and Keilbach M. (2007) The localisation of entrepreneurship capital: Evidence from Germany, Papers in Regional Science, 86, 351-365;

Audretsch D.B. and Keilbach M. (2008) Resolving the knowledge paradox: Knowledgespillover entrepreneurship and economic growth, Research Policy, 37, 1697-1705;

Audretsch, D.B., Bönte, W. and Keilbach, M. (2008). Entrepreneurship capital and its impact on knowledge diffusion and economic performance. Journal of Business Venturing 23, 687-698;

Baptista R. and Preto M.T. (2007) New Firm Formation and Employment Growth: Differences between Regions, 47th Congress of the ERSA, Paris, France, August 29thSeptember 2nd;

Baumgartner D., Putz M. and Seidl I. (2013) What Kind of Entrepreneurship Drives Regional Development in European Non-core Regions? A Literature Review on Empirical Entrepreneurship Research, European Planning Studies, 21, 1095-1127; 
Beaudry C. and Schiffauerova A. (2009) Who's right, Marshall or Jacobs? The localization versus urbanization debate, Research Policy 38, 318-337;

Boschma R. and Lambooy J. (1999) Evolutionary economics and economic geography, Journal of Evolutionary Economics, 9, 411-429;

Cabral L. M. B. and Mata J. (2003) On the Evolution of the Firm Size Distribution: Facts and Theory, American Economic Review, 93, 1075-90;

Cesário, M. and Vaz M.-T. (2004) Territory and entrepreneurial performance - An exercise on some industrial Portuguese regions, ERSA conference papers ersa04p179, European Regional Science Association;

Cohen W.M. and Levinthal D.A. (1989) Innovation and learning: the two faces of R\&D, The Economic Journal, 99, 569-596;

de Vor F. and de Groot H. (2010) Agglomeration externalities and localized employment growth: the performance of industrial sites in Amsterdam, Annals of Regional Science 44:409-431;

Driscoll, J. C., and Kraay A.C. (1998) Consistent Covariance Matrix Estimation with Spatially Dependent Panel Data, Review of Economics and Statistics, 80, 549-560;

Eckey H.F., Schwengler B. and Türck M. (2007) Vergleich von deutschen Arbeitsmarktregionen, IAB Discussion Paper No. 3/2007, Nuremberg;

Faria, P. and Schmidt T. (2012) International cooperation on innovation: firm-level evidence from two European countries, Innovation: Management, Policy \& Practice, 14, 303-323;

Faria, P. and Sofka W. (2010) Knowledge Protection Strategies of Multinational Firms - a Cross-Country Comparison, Research Policy, 39, 956-968;

Feldman M.P. and Audretsch D.B. (1999) Innovation in cities: Science-based diversity, specialization and localized competition, European Economic Review, 43, 409-429;

Fritsch M. and Falk O. (2007) New Firm Formation by Industry over Space and Time: A Multi-Level Analysis, Regional Studies, 41, 157-172;

GEM Report (2004) Global Entrepreneurship Monitor, 2004 Executive Report, http://www.gemconsortium.org/report;

GEM Report (2014) Global Entrepreneurship Monitor, 2014 Global Report, http://www.gemconsortium.org/report;

Geroski P.A. (1995) What do we know about entry?, International Journal of Industrial Organization, 13, 421-440; 
Glaeser E.L., Kallal H.D., Scheinkman J.A. and Shleifer A. (1992) Growth in Cities, Journal of Political Economy, 100, 1126-1152;

Griliches Z. (1979) Issues in Assessing the Contribution of Research and Development to Productivity Growth, Bell Journal of Economics, 10, 92-116;

Grimpe C. and Patuelli R. (2011) Regional knowledge production in nanomaterials: a spatial filtering approach, Annals of Regional Science, 46, 519-541;

Hidalgo C. and Hausmann R. (2009) The building blocks of economic complexity, Proceedings of the National Academy of Sciences of the United States of America, 106: 10570-10575;

Heitor M., Horta H. and Mendonça J. (2014) Developing human capital and research capacity: science policies promoting brain gain, Technological Forecasting and Social Change, 82, 6-22;

Jaffe A.B., Trajtenberg M. and Henderson R. (1993) Geographic Localization of Knowledge Spillovers as Evidenced by Patent Citations, The Quarterly Journal of Economics, 108, 577-598;

Lee S., Florida R. and Acs Z. (2004) Creativity and Entrepreneurship: A Regional Analysis of New Firm Formation, Regional Studies, 38, 879-891;

Lucas R. (1988) On the mechanics of economic development, Journal of Monetary Economics, 22, 3-42;

Maskell P. and Malmberg A. (1999) Localised learning and industrial competitiveness Cambridge Journal of Economics, 23, 167-185;

Marshall A. (1920) Principles of Economics, 8th edition, Macmillan, London;

Rosenthal S.S. and Strange W.C. (2005) The Geography of Entrepreneurship in the New York Metropolitan Area, FRBNY Economic Policy Review, December 2005: 29-53;

Shane S. (2000) Prior Knowledge and the Discovery of Entrepreneurial Opportunities, Organization Science, 11, 448-469;

Zucker L., Darby M.R. and Armstrong J. (1998) Intellectual Human Capital and the Birth of U.S. Biotechnology Enterprises, American Economic Review, 88, 290-306. 


\section{Tables and Figures}

Table 1: Economic characteristics of Germany and Portugal

\begin{tabular}{lll}
\hline & Germany & Portugal \\
\hline GDP 1998 (billion EUR) & 1952 & 106 \\
GDP 2000 (billion EUR) & 2063 & 122 \\
Income pc (EUR) & 29,115 & 14,161 \\
Gini coefficient & 28.3 & 38.5 \\
Human development index & 0.93 & 0.90 \\
Unemployment rate 1998 (\%) & 9.1 & 5.1 \\
Unemployment rate 2000 (\%) & 7.5 & 4.0 \\
Inflation rate 1998 (\%) & 0.6 & 2.2 \\
Inflation rate 2000 (\%) & 1.4 & 2.8 \\
Population 2007 (million) & 82.6 & 10.4 \\
Population in urbanized regions (\%) & 88.1 & 60.9 \\
Area (square km) & 357,022 & 91,982 \\
Population per square km & 231 & 114 \\
\hline
\end{tabular}

Source: Eurostat; Human Development Report 2007

Table 2: $\quad$ Descriptive statistics - Portugal

\begin{tabular}{llllll}
\hline Variable & Obs. & Mean & Std. Dev. & Min & Max \\
\hline Startup rate - all industries & 140 & 7.64 & 3.33 & 2.38 & 18.961 \\
Startup rate - high-tech manufacturing & 140 & 0.05 & 0.06 & 0 & 0.41 \\
Startup rate - techn.-/knowl.-int. services & 140 & 0.52 & 0.24 & 0.13 & 1.78 \\
Human capital & 140 & 0.06 & 0.02 & 0.02 & 0.16 \\
Skill specialization & 140 & 0.33 & 0.19 & 0 & 0.62 \\
Population (in logs) & 140 & 12.21 & 0.89 & 10.02 & 14.49 \\
GDP growth (\%) & 140 & 0.05 & 0.03 & -0.05 & 0.15 \\
Unemployment rate (\%) & 140 & 4.83 & 2.12 & 1.36 & 12.29 \\
\hline
\end{tabular}

Note: Region-year observations

Table 3: Descriptive statistics - Germany

\begin{tabular}{llllll}
\hline Variable & Obs. & Mean & Std. Dev. & Min & Max \\
\hline Startup rate - all industries & 2195 & 4.45 & 1.26 & 1.82 & 14.34 \\
Startup rate - high-tech manufacturing & 2195 & 0.04 & 0.03 & 0 & 0.36 \\
Startup rate - techn.-/knowl.-int. services & 2195 & 0.51 & 0.28 & 0 & 2.75 \\
Human capital & 2195 & 0.08 & 0.04 & 0.02 & 0.26 \\
Skill specialization & 2195 & 0.56 & 0.11 & 0.23 & 1.00 \\
Population (in logs) & 2195 & 11.90 & 0.63 & 10.48 & 15.04 \\
GDP growth (\%) & 2195 & 1.98 & 3.62 & -19.83 & 26.27 \\
Unemployment rate (\%) & 2195 & 10.38 & 5.42 & 2.60 & 29.30 \\
\hline
\end{tabular}

Note: Region-year observations 
Table 4: Pooled OLS regression results for Portugal

\begin{tabular}{llll}
\hline & & \multicolumn{2}{l}{ Entrepreneurship capital } \\
Explanatory Variables & All & High-med.-tech. & Techn.-/knowl.-int. serv. \\
\hline Human capital & $-52.800^{* * *}$ & 0.030 & 0.965 \\
& $(8.526)$ & $(0.092)$ & $(1.225)$ \\
Skill Specialization & 2.648 & $0.173 * * *$ & 0.218 \\
& $(3.318)$ & $(0.015)$ & $(0.159)$ \\
Population (in logs) & $1.853^{* * *}$ & $0.022^{* * *}$ & $0.146^{* *}$ \\
& $(0.296)$ & $(0.004)$ & $(0.040)$ \\
GDP growth & $6.174^{* * *}$ & -0.189 & $0.543^{*}$ \\
& $(0.789)$ & $(0.157)$ & $(0.253)$ \\
Unemployment rate & 0.024 & -0.008 & -0.011 \\
& $(0.063)$ & $(0.005)$ & $(0.012)$ \\
Year dummies & included & included & included \\
Province dummies & included & included & included \\
\hline R2 & 0.729 & 0.299 & 0.525 \\
Region-year observations & 140 & 140 & 140 \\
Number of groups & 28 & 28 & 28 \\
\hline$*$ p $<0.10, * * \mathrm{p}<0.05, * * * \mathrm{p}<0.01 ;$ Driscoll-Kraay standard errors in parentheses & \\
\hline
\end{tabular}

Table 5: Pooled OLS regression results for Germany

\begin{tabular}{|c|c|c|c|}
\hline \multirow[b]{2}{*}{ Explanatory Variables } & \multicolumn{3}{|c|}{ Entrepreneurship capital } \\
\hline & All & High-med.-tech. & Knowl.-int. services \\
\hline \multirow[t]{2}{*}{ Human capital } & $8.193 * * *$ & $0.077 * *$ & $3.744^{* * *}$ \\
\hline & $(0.224)$ & $(0.026)$ & $(0.145)$ \\
\hline \multirow[t]{2}{*}{ Skill Specialization } & $-1.727 * * *$ & $-0.011^{*}$ & $-0.355^{* * *}$ \\
\hline & $(0.099)$ & $(0.006)$ & $(0.012)$ \\
\hline \multirow[t]{2}{*}{ Population (in logs) } & $-0.143^{* *}$ & $-0.004 * * *$ & 0.014 \\
\hline & $(0.042)$ & $(0.001)$ & $(0.010)$ \\
\hline \multirow[t]{2}{*}{ GDP growth } & 0.004 & -0.000 & 0.001 \\
\hline & $(0.007)$ & $(0.000)$ & $(0.001)$ \\
\hline \multirow[t]{2}{*}{ Unemployment rate } & -1.691 & $-0.118 * * *$ & $-0.900 * *$ \\
\hline & $(0.991)$ & $(0.019)$ & $(0.205)$ \\
\hline Year dummies & included & included & included \\
\hline Laender dummies & included & included & included \\
\hline R2 & 0.264 & 0.054 & 0.418 \\
\hline Region-year observations & 2195 & 2195 & 2195 \\
\hline Number of groups & 439 & 439 & 439 \\
\hline
\end{tabular}


Figure 1: Startup rate by NUTS-3 regions (average 2000-2004) in Portugal

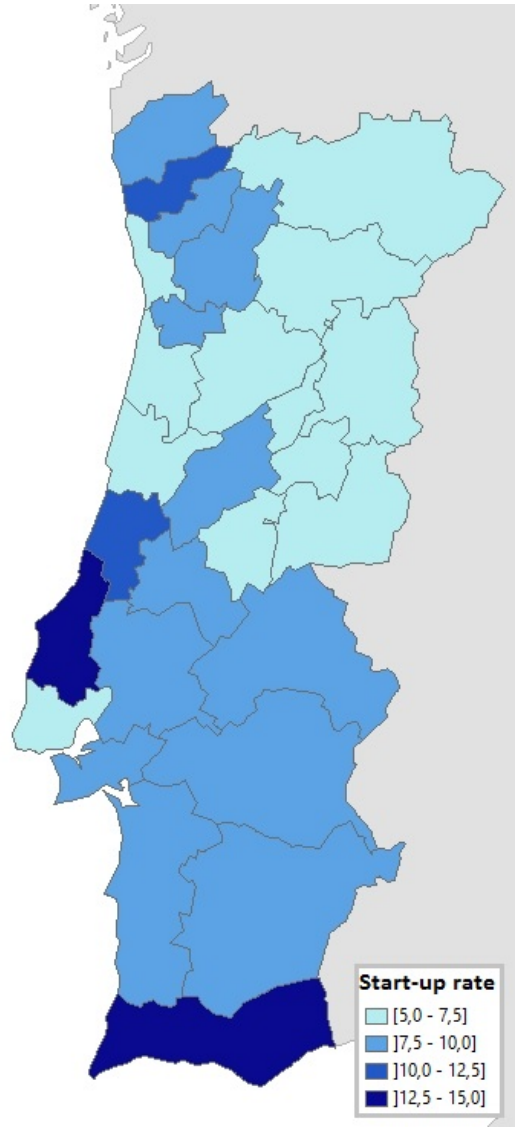


Figure 2: Startup rate by NUTS-3 regions (average 2000-2004) in Germany

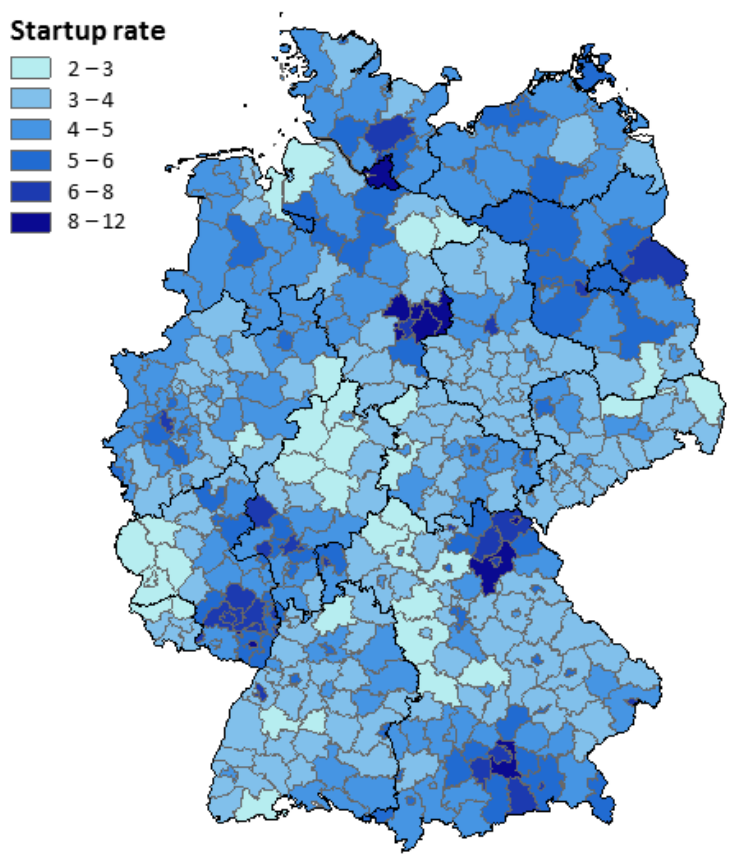

